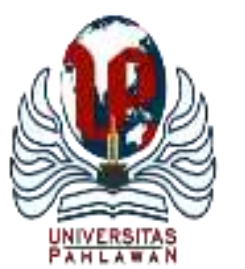

Edukatif : Jurnal Ilmu Pendidikan Volume 4 Nomor 1 Tahun 2022 Halm 233 - 239

EDUKATIF: JURNAL ILMU PENDIDIKAN

Research \& Learning in Education

https://edukatif.org/index.php/edukatif/index

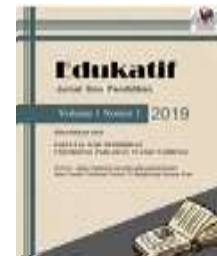

\title{
Pemetaan Bibliometrik Terhadap Riset pada Sekolah Menengah Kejuruan Menggunakan VOSviewer
}

\section{Hendra Sahputra Batubara ${ }^{1}$, Muhammad Giatman², Wakhinuddin Simatupang ${ }^{3}$, Ronal Watrianthos ${ }^{4 \times}$}

Sekolah Menengah Kejuruan Imelda, Medan, Indonesia ${ }^{1}$, Program Studi Pendidikan Teknologi dan Kejuruan, Universitas Negeri Padang, Padang, Indonesia ${ }^{2,3}$, Program Studi Teknik Informatika, Universitas Al

Washliyah Labuhanbatu, Rantauprapat, Indonesia ${ }^{4}$,

E-mail : hendrabatubara4@gmail.com ${ }^{1}$, giatman@ $\mathrm{ft.unp.ac.id}^{2}, \underline{\text { wakhinuddins@gmail.com }}^{3}$, ronal.watrianthos@gmail.com ${ }^{4}$

\begin{abstract}
Abstrak
Revitalisasi SMK pada saat ini secara langsung memaksa seluruh sarana prasarana pendukung harus meningkatkan kompetensi sesuai standar industri. Misalnya pada peningkatan kompetensi guru yang menjadi kewajiban dan tidak bisa diselesaikan secara instan. Beberapa publikasi terkait peningkatan kompetensi guru ini sudah banyak dilakukan, namun publikasi mengenai revitalisasi SMK masih dirasa minim. Penelitian ini bertujuan memetakan dengan metode bibiliometrik riset-riset mengenai SMK. Pencarian artikel penelitian dilakukan dengan menggunakan aplikasi Harzing's Publish or Perish dengan menggunakan kata kunci "Sekolah Menengah Kejuruan" pada artikel berbahasa Indonesia. Hasil pemetaan menggunakan VOSviewer jumlah publikasi terbanyak pada tahun 2020 dengan 165 publikasi dengan Universitas Negeri Malang sebagai institusi terbanyak dalam menghasilkan publikasi. Sedangkan analisis terhadap topik penelitian terkait SMK berhubungan dengan topik seperti 'Pengembangan', 'Analisis', 'Studi Kasus', dan 'Manajemen' sehingga risetriset terkait SMK lebih banyak berhubungan pada topik ini.
\end{abstract}

Kata Kunci: bibliometrik, riset, sekolah menengah kejuruan, VOSviewer

\section{Abstract}

The ongoing revival of vocational high schools puts all supporting infrastructure under direct pressure to increase competence in accordance with industry norms. Improving teacher competency, for example, is a requirement that cannot be met overnight. Several articles on strengthening teacher competency have been extensively distributed, while writings on revitalizing SMK are still deemed inadequate. The purpose of this study is to map the bibliometric approach of research on SMK. Harzing's Publish or Perish tool was used to search for research publications in Indonesian articles using the phrase "Vocational High School." The results of mapping using VOSviewer had the maximum number of publications in 2020 with 165 articles, with Malang State University being the most prolific producer of publications. While the study of research themes connected to SMK links to topics such as "development," "analysis," "case studies", and "management,' research on SMK is more relevant to this issue.

Keywords: bibliometrics, research, vocational high school, VOSviewer

Copyright (c) 2022 Hendra Sahputra Batubara, Muhammad Giatman, Wakhinuddin Simatupang, Ronal Watrianthos

$\triangle$ Corresponding author

Email : ronal.watrianthos@gmail.com

DOI : https://doi.org/10.31004/edukatif.v4i1.1818 
234 Pemetaan Bibliometrik Terhadap Riset pada Sekolah Menengah Kejuruan Menggunakan VOSviewerHendra Sahputra Batubara, Muhammad Giatman, Wakhinuddin Simatupang, Ronal Watrianthos DOI: https://doi.org/10.31004/edukatif.v4i1.1818

\section{PENDAHULUAN}

Pendidikan kejuruan dan pelatihan keterampilan kerja merupakan dua arah kebijakan pemerintah di bidang pendidikan vokasi. Presiden Indonesia dalam mewujudkan cita-cita tersebut telah mengeluarkan Instruksi Presiden Nomor 9 Tahun 2016 tentang Sekolah Menengah Kejuruan dalam rangka peningkatan kemampuan sumber daya manusia Indonesia untuk bersaing di kancah internasional. Hasil yang diharapkan adalah tenaga kerja yang terlatih dan kompetitif yang mampu memenuhi kebutuhan dunia bisnis dan industri yang semakin berkembang. Namun, menurut Badan Pusat Statistik (BPS), persentase pengangguran terbesar pada Agustus 2017 adalah lulusan Sekolah Menengah Kejuruan (SMK) (Kependidikan, 2018).

Dalam penyelenggaraan pendidikan vokasi, penyelarasan difokuskan pada penguatan industrial, program afirmasi, dan job matching bagi lulusan SMK. Lulusan SMK harus siap di bidang-bidang seperti Teknologi Informasi dan Komunikasi (TIK), bahasa asing, kewirausahaan, dan interaksi sekolah-bisnis (Putri \& Supriansyah, 2021). Sekolah dan DUDI harus bersinergi untuk melaksanakan pembelajaran di SMK. Siswa SMK wajib diajarkan teknik industri oleh DUDI agar menjadi calon tenaga kerja yang terampil dan kompeten (Cholik et al., 2020) (Moses, 2017) (Saputra et al., 2021).

Revitalisasi SMK pada saat ini secara langsung memaksa seluruh sarana prasarana pendukung harus meningkatkan kompetensi sesuai standar industri. Proses peningkatan kompetensi guru menjadi kewajiban dan tidak bisa diselesaikan secara instan (Hartanti \& Yuniarsih, 2018). Sebagai pendidik, guru harus selalu siap dengan pengetahuan baru yang dapat digunakan dalam konteks pembelajaran. Beberapa publikasi terkait peningkatan kompetensi guru SMK sudah banyak dilakukan (Oka, 2021). Misalnya pada SMK Dhuafa Nusantara Padang dan SMK Muhammadiyah 1 Padang terkait dengan peningkatan kompetensi dibidang TIK terutama pada perangkat lunak AutoCAD dalam teknik menggambar dan PLC dalam pembelajaran sistem kendali (Eliza et al., 2019).

Beberapa perguruan tinggi di Jawa Tengah juga menerapkan inisiatif untuk membantu guru SMK memperkuat keterampilan kewirausahaan mereka. Guru dilatih dalam model pengembangan pembelajaran kewirausahaan untuk membekali siswa dengan keterampilan jangka panjang yang memungkinkan siswa untuk mandiri ketika mereka meninggalkan sekolah (Suryandari et al., 2021). Bahkan kompetensi guru SMK juga ditingkatkan melalui pelatihan penulisan artikel ilmiah di SMKN Sidoarjo (Suryandari et al., 2021). Hasil didapatkan adalah terjadi peningkatan pengetahuan penulisan artikel ilmiah sebesar $58 \%$, dan motivasi dalam mengunggah artikel di jurnal nasional sebesar 54\%.

Riset mengenai SMK sudah banyak dilakukan, namun dirasa masih kurang terutama dalam misi revitalisasi yang diprogramkan pemerintah. Penelitian ini bermaksud memetakan secara bibiliometrik risetriset mengenai SMK. Dalam analisis bibliometrik, data dari berbagai sumber, seperti artikel, jurnal, dan karya sastra lainnya, dianalisis untuk menentukan pola dan tren. Bibliometrik adalah strategi statistik yang menggunakan sarana matematika untuk memeriksa publikasi penelitian yang terhubung secara statistik pada topik tertentu (Aribowo, 2019) (Yu et al., 2020).

\section{METODE PENELITIAN}

Metode yang digunakan adalah bibliometrik dengan meringkas beberapa artikel dengan topik tertentu. Pencarian artikel penelitian dilakukan dengan menggunakan aplikasi Harzing's Publish or Perish pada tanggal menggunakan kata kunci "Sekolah Menengah Kejuruan" pada artikel berbahasa Indonesia. Data kemudian disimpan dalam bentuk ekstensi ris yang kemudian dianalisis menggunakan aplikasi VOSviewer untuk mendapatkan visualisasi dalam peta bibliometrik. Terdapat 1000 artikel dalam bahasa Indonesia yang dihasilkan dan diseleksi sesuai kriteria yang diinginkan sehingga menjadi 859 publikasi yang dianalisis dalam bentuk peta bibliometrik. Tahapan penelitian dapat dilihat pada Gambar 1. 
235 Pemetaan Bibliometrik Terhadap Riset pada Sekolah Menengah Kejuruan Menggunakan VOSviewer Hendra Sahputra Batubara, Muhammad Giatman, Wakhinuddin Simatupang, Ronal Watrianthos

DOI: https://doi.org/10.31004/edukatif.v4i1.1818

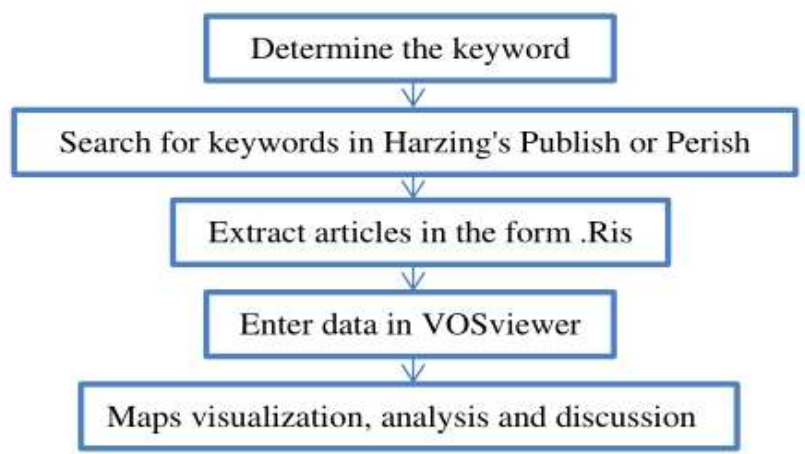

Gambar 1: Tahapan Penelitian (Suliyanah et al., 2021)

\section{HASIL DAN DISKUSI}

Dari proses pengumpulan meta data terkait riset-riset terhadap SMK dengan kata kunci "Sekolah Menengah Kejuruan" menghasilkan 1000 dokumen menggunakan software Publish or Perish (POP). Penelitian terhadap metadata ini belum pernah dilakukan sebelumnya. Metadata artikel diunduh dan diseleksi kembali sesuai kategori terutama kelengkapan nama, afiliasi, tahun, dan penerbit sehingga artikel yang dianalisis tinggal menjadi 859 artikel. Gambar 2 merupakan perkembangan fluktuatif jumlah artikel yang terkait dengan kata kunci selama 10 tahun dimulai tahun 2011 sampai dengan tahun 2021.

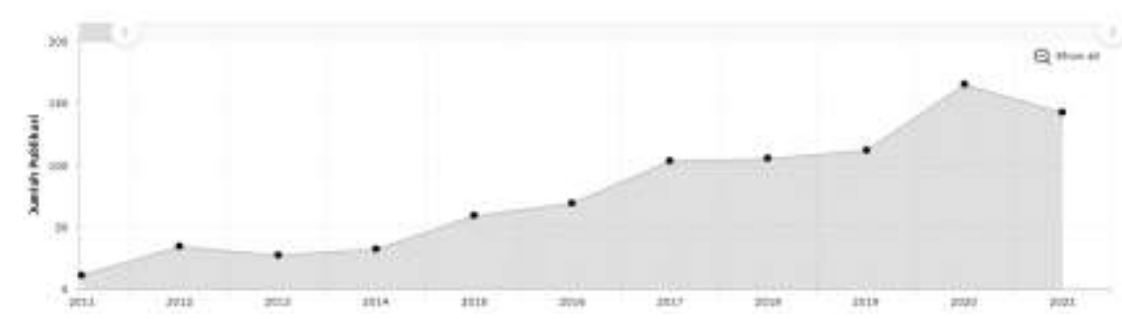

Gambar 2: Jumlah Publikasi Pada kata kunci 'SMK' Pada Tahun 2011-2021

Pada gambar 2 terlihat jumlah publikasi tertinggi ada pada tahun 2020 dengan 165 publikasi terkait dengan SMK. Diikuti tahun 2021 dengan 142 publikasi dan tahun 2019 sebanyak 142 publikasi. Kenaikan signifikan jumlah publikasi terjadi sejak tahun 2016 seiring dengan syarat wajib publikasi ilmiah secara online pada setiap jenjang Pendidikan. Peringkat teratas untuk publikasi yang berhubungan dengan SMK ini adalah Universitas Negeri Malang diikuti dengan Universitas Negeri Yogyakarta dan Universitas Negeri Padang bersama Universitas Sarjanawiyata Tamansiswa seperti yang ditunjukkan pada gambar 3 di bawah ini dengan minimal 10 publikasi.

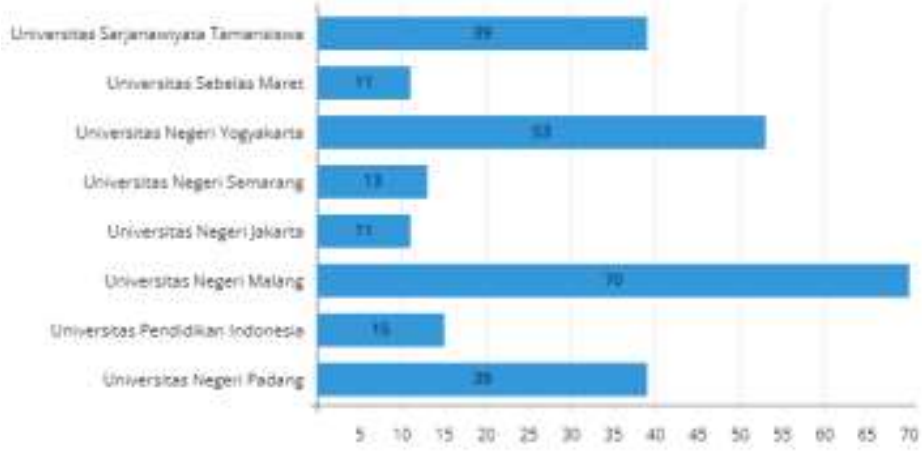

Gambar 3: Delapan Besar Untuk Publikasi Terbanyak

Edukatif : Jurnal Ilmu Pendidikan Vol 4 No 1 Tahun 2022 p-ISSN 2656-8063 e-ISSN 2656-8071 
236 Pemetaan Bibliometrik Terhadap Riset pada Sekolah Menengah Kejuruan Menggunakan VOSviewerHendra Sahputra Batubara, Muhammad Giatman, Wakhinuddin Simatupang, Ronal Watrianthos

DOI: https://doi.org/10.31004/edukatif.v4i1.1818

Menggunakan software VOSviewer, hasil metadata dari software POP dapat dikalkulasikan peneliti yang paling aktif menghasilkan publikasi terkait SMK. Tabel 1 menunjukkan hasil analisis VOSviewer dengan metode full counting dengan kriteria maksimal 20 peneliti dalam satu publikasi dan minimum 5 publikasi pada setiap peneliti menghasilkan lima peneliti terproduktif terkait SMK.

Tabel 1: Peneliti Paling Produktif

\begin{tabular}{clcc}
\hline No & \multicolumn{1}{c}{ Nama } & $\begin{array}{c}\text { Jumlah } \\
\text { Publikasi }\end{array}$ & Institusi \\
\hline 1 & Sukardi & 7 & Universitas Negeri Padang \\
2 & Reni Farwitawati & 5 & Universitas Lancang Kuning \\
3 & Amat Mukhadis & 5 & Universitas Negeri Malang \\
4 & Sri Rahayu & 5 & Sekolah Tinggi Teknologi Garut \\
5 & Sutrisno & 5 & Universitas Negeri Malang \\
\hline
\end{tabular}

Tabel 1 menunjukkan Sukardi dari Universitas Negeri Padang menjadi peneliti paling produktif dalam pemetaan bibliometrik terhadap penelitian terkait SMK. Sedangkan peneliti lain memiliki jumlah publikasi yang sama berdasarkan kriteria yang ditentukan dalam VOSviewer.

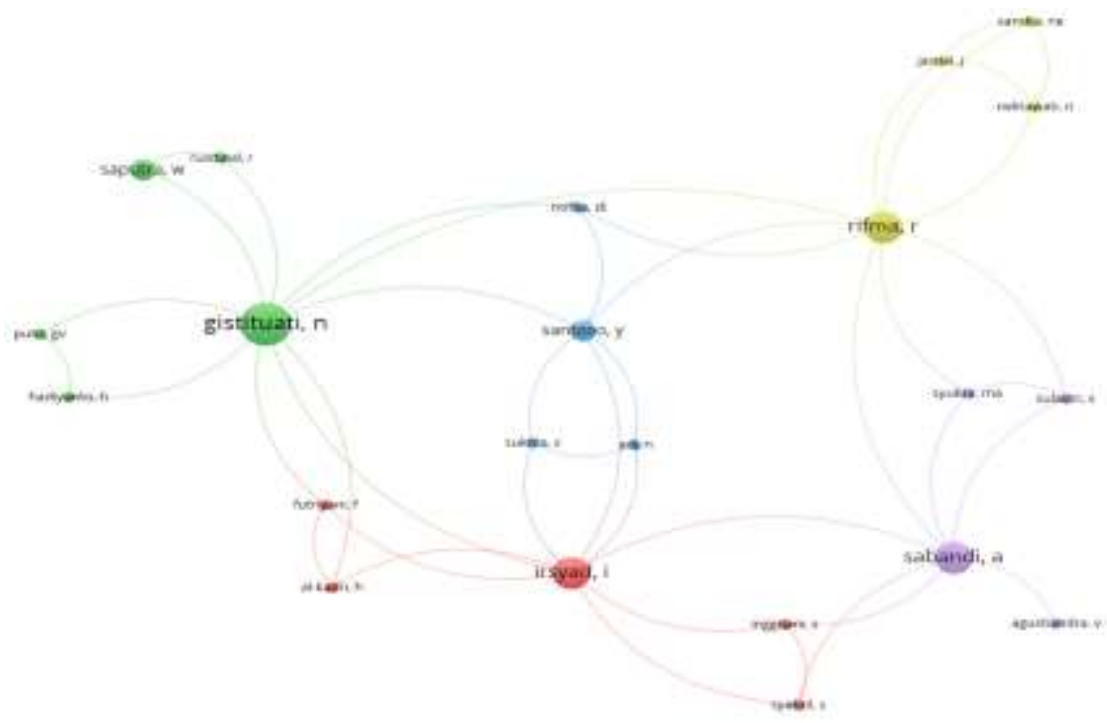

Gambar 4: Kluster Peneliti Menggunakan VOSviewer

Seperti terlihat pada gambar 4 terdapat empat kluster peneliti yang saling berkolaborasi terkait SMK Hasil analisa ini berdasarkan kriteria 3 publikasi minimal pada setiap author sehingga menghasilkan 30 kluster yang saling berhubungan dan 5 kluster terbesar seperti ditunjukkan pada tabel 2 .

Tabel 2: Lima Kluster Terbesar Peneliti

\begin{tabular}{ccccl}
\hline No & \multicolumn{1}{c}{ Nama } & Jumlah Publikasi & Bobot Total Tautan & \multicolumn{1}{c}{ Institusi } \\
\hline 1 & Nurhizrah Gistituati & 4 & 2 & Universitas Negeri Padang \\
2 & I Irsyad & 3 & 2 & Universitas Negeri Malang \\
3 & R Rifma & 3 & 2 & Universitas Negeri Yogyakarta \\
4 & Sabandi & 3 & 2 & Universitas Negeri Padang \\
\hline
\end{tabular}

Sedangkan hasil analisis terhadap topik penelitian terkait SMK berdasarkan judul publikasi didapatkan judul yang menggunakan kata 'Sekolah Menengah Kejuruan' total bobot tautan 41 dengan kemunculan pada 
237 Pemetaan Bibliometrik Terhadap Riset pada Sekolah Menengah Kejuruan Menggunakan VOSviewerHendra Sahputra Batubara, Muhammad Giatman, Wakhinuddin Simatupang, Ronal Watrianthos DOI: https://doi.org/10.31004/edukatif.v4i1.1818

publikasi sebanyak 495 kali. Kluster 'Sekolah Menengah Kejuruan' dalam analisis VOSviewer ini kemudian diikuti dengan kluster utama lainnya seperti 'Pengembangan', 'Analisis', 'Studi Kasus', dan 'Manajemen'. Hal ini membuktikan penelitian terhadap SMK lebih banyak membahas pada topik-topik tersebut seperti ditunjukkan pada Gambar 5 berikut.

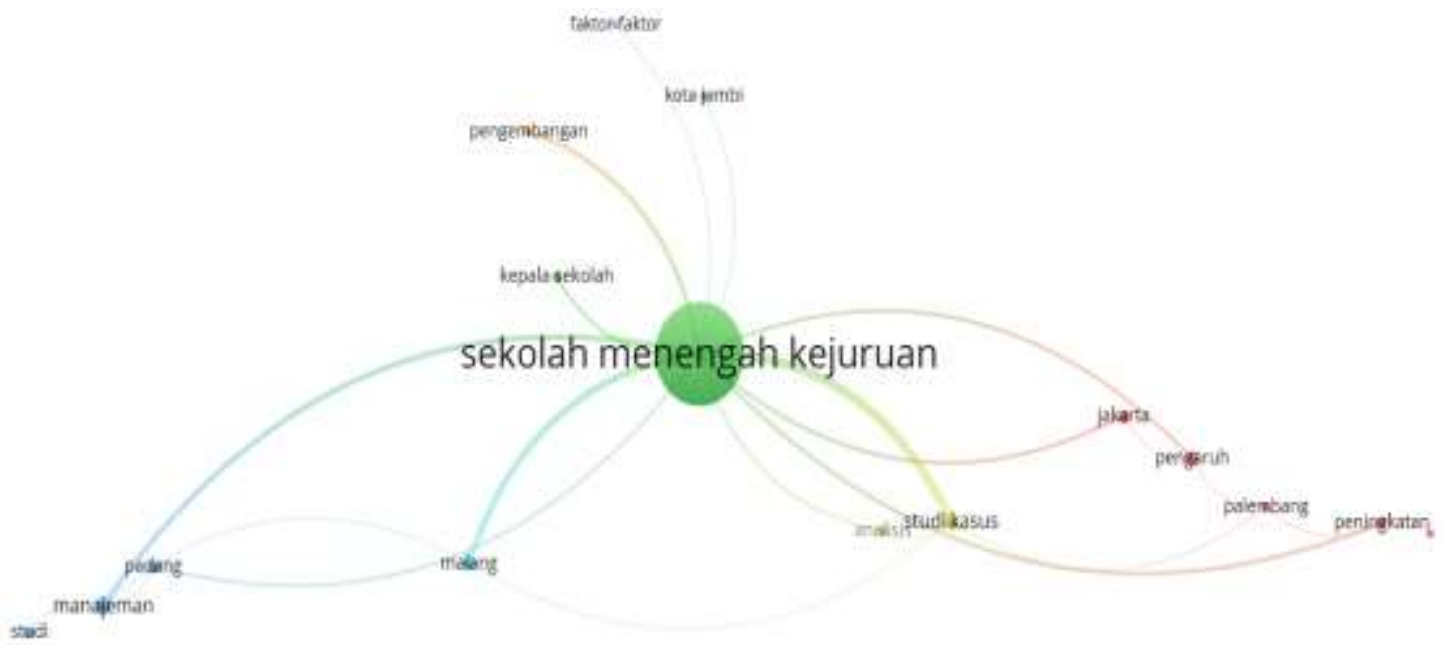

Gambar 5: Kluster Topik Penelitian Menggunakan VOSviewer

Berdasarkan kata kunci yang digunakan dalam penelitian ini, juga didapatkan jumlah sitasi setiap artikel. Hasil analisis menggunakan software POP dan Mendeley dengan pengambilan data pada bulan Desember 2021, didapatkan 5 artikel yang memiliki sitasi tertinggi seperti yang ditunjukkan pada tabel 3 di bawah ini.

Tabel 3: Artikel dengan Sitasi Tertinggi Pada Tahun 2021

\begin{tabular}{|c|c|c|c|c|c|}
\hline No & $\underset{\mathbf{i}}{\text { Sitas }}$ & $\begin{array}{l}\text { Nama } \\
\text { Penulis }\end{array}$ & $\begin{array}{c}\text { Judul } \\
\text { Artikel }\end{array}$ & $\begin{array}{c}\text { Nama } \\
\text { Publikasi }\end{array}$ & Penerbit \\
\hline 1 & 159 & Hary Susanto & 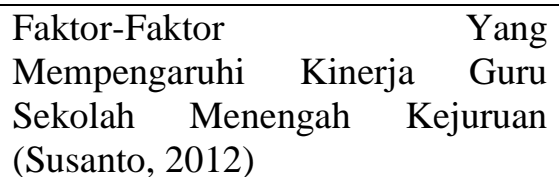 & $\begin{array}{l}\text { Jurnal } \\
\text { Pendidikan } \\
\text { Vokasi }\end{array}$ & $\begin{array}{c}\text { Universitas Negeri } \\
\text { Yogyakarta }\end{array}$ \\
\hline 2 & 100 & $\begin{array}{l}\text { Nugroho } \\
\text { Wibowo }\end{array}$ & $\begin{array}{l}\text { Upaya Memperkecil Kesenjangan } \\
\text { Kompetensi Lulusan Sekolah } \\
\text { Menengah Kejuruan dengan } \\
\text { Tuntutan Dunia Industri (Wibowo, } \\
2016 \text { ) }\end{array}$ & $\begin{array}{l}\text { Jurnal } \\
\text { Pendidikan } \\
\text { Teknologi } \\
\text { Kejuruan }\end{array}$ & $\begin{array}{c}\text { Universitas Negeri } \\
\text { Yogyakarta }\end{array}$ \\
\hline 4 & 59 & $\begin{array}{l}\text { Yudi Ganing } \\
\text { Dwi Utami dan } \\
\text { Hudaniah }\end{array}$ & $\begin{array}{l}\text { Self-Efficacy Dengan Kesiapan } \\
\text { Kerja Siswa Sekolah Menengah } \\
\text { Kejuruan (Wibowo, 2016) }\end{array}$ & $\begin{array}{l}\text { Jurnal Ilmiah } \\
\text { Psikologi }\end{array}$ & $\begin{array}{l}\text { Muhammadiyah } \\
\text { Malang }\end{array}$ \\
\hline 5 & 47 & $\begin{array}{l}\text { Aliangga } \\
\text { Kusumam, } \\
\text { Mukhidin } \\
\text { Mukhidin, } \\
\text { Bachtiar Hasan } \\
\text { Ati Siti }\end{array}$ & $\begin{array}{l}\text { Pengembangan Bahan Ajar Mata } \\
\text { Pelajaran Dasar dan Pengukuran } \\
\text { Listrik untuk Sekolah Menengah } \\
\text { Kejuruan (Kusumam et al., 2016) }\end{array}$ & $\begin{array}{l}\text { Jurnal } \\
\text { Pendidikan } \\
\text { Teknologi } \\
\text { Kejuruan }\end{array}$ & $\begin{array}{c}\text { Universitas Negeri } \\
\text { Yogyakarta }\end{array}$ \\
\hline
\end{tabular}


Pemetaan Bibliometrik Terhadap Riset pada Sekolah Menengah Kejuruan Menggunakan VOSviewerHendra Sahputra Batubara, Muhammad Giatman, Wakhinuddin Simatupang, Ronal Watrianthos DOI: https://doi.org/10.31004/edukatif.v4i1.1818

\begin{tabular}{lcllcc}
\hline No & $\begin{array}{c}\text { Sitas } \\
\text { i }\end{array}$ & $\begin{array}{l}\text { Nama } \\
\text { Penulis }\end{array}$ & \multicolumn{1}{c}{$\begin{array}{c}\text { Judul } \\
\text { Artikel }\end{array}$} & $\begin{array}{c}\text { Nama } \\
\text { Publikasi }\end{array}$ & Penerbit \\
\hline & Rochayati dan & Faktor-Faktor $\quad$ Yang & & Soedirman \\
& Eyet Hidayat & $\begin{array}{l}\text { Mempengaruhi Perilaku Merokok } \\
\text { Remaja Di Sekolah Menengah }\end{array}$ & \\
& & $\begin{array}{l}\text { Kejuruan Kabupaten Kuningan } \\
\text { (Rochayati \& Hidayat, 2015) }\end{array}$ & $\begin{array}{c}\text { Jurnal } \\
\text { Keperawatan } \\
\text { Soedirman }\end{array}$ & \\
& & & & \\
& & &
\end{tabular}

Analisis menunjukkan publikasi berjudul 'Faktor-Faktor Yang Mempengaruhi Kinerja Guru Sekolah Menengah Kejuruan' dengan penulis Hary Susanto pada Jurnal Pendidikan Vokasi mendapatkan sitasi tertinggi dengan jumlah sitasi 159. Hasil penelitian menunjukkan terdapat pengaruh positif dan signifikan terhadap kompetensi guru dan kepemimpinan kepala sekolah terhadap motivasi kerja guru SMK di Kabupaten Hulu Sungai Selatan. Sitasi tertinggi kemudian diikuti dengan Nugroho Wibowo dengan judul 'Upaya Memperkecil Kesenjangan Kompetensi Lulusan Sekolah Menengah Kejuruan dengan Tuntutan Dunia Industri' yang terbit pada Jurnal Pendidikan Teknologi Kejuruan dengan jumlah sitasi 100. Artikel ini menemukan untuk memperkecil kesenjangan antara SMK dengan industry perlu ditingkatkan program teaching factory, prakerin, kunjungan industry, dan on job training,

\section{KESIMPULAN}

Hasil pemetaan bibliometrik terhadap riset dengan topik Sekolah Menengah Kejuruan (SMK) menggunakan VOSviewer dan Publish or Perish pada periode tahun 2011 - 2021 menghasilkan 859 artikel terkait. Jumlah publikasi terbanyak ada pada tahun 2020 dengan 165 publikasi dengan Universitas Negeri Malang sebagai institusi tertinggi dalam menghasilkan publikasi. Hasil analisis terhadap topik penelitian terkait SMK berhubungan dengan topik lain seperti 'Pengembangan', 'Analisis', 'Studi Kasus', dan 'Manajemen' sehingga riset-riset terkait SMK lebih banyak berhubungan pada topik ini. Penelitian ini diharapkan memberi kontribusi terhadap penelitian-penelitian terkait mengenai SMK agar bisa digali lagi potensi dan revitalisasi SMK di masa depan.

\section{REFERENSI}

Aribowo, E. K. (2019). Analisis Bibliometrik Berkala Ilmiah Names: Journal Of Onomastics Dan Peluang Riset Onomastik Di Indonesia. Aksara, 31(1), 85. Https://Doi.Org/10.29255/Aksara.V31i1.373.85-105

Cholik, M., Ekohariadi, Putra, R. E., \& Utami, A. W. (2020). Revitalisasi Smk Dalam Peningkatan Kompetensi Lulusan Untuk Beradaptasi Di Dunia Industri. Kementrian Pendidikan Dan Kebudayaan.

Eliza, F., Hastuti, H., Myori, D. E., \& Yanto, D. T. P. (2019). Peningkatan Kompetensi Guru Sekolah Menengah Kejuruan Melalui Pelatihan Software Engineering. Jurnal Teknik Elektro Dan Vokasional, 5(1). Https://Doi.Org/Https://Doi.Org/10.24036/Jtev.V5i1.104840

Hartanti, A. S., \& Yuniarsih, T. (2018). Pengaruh Kompetensi Profesional Guru Dan Motivasi Kerja Terhadap Kinerja Guru Di Sekolah Menengah Kejuruan. Jurnal Pendidikan Manajemen .... Https://Ejournal.Upi.Edu/Index.Php/Jpmanper/Article/View/9452

Kependidikan, D. J. G. Dan T. (2018). Revitalisasi Smk Pemenuhan Dan Peningkatan Profesionalitas Guru. Kementrian Pendidikan Dan Kebudayaan.

Kusumam, A., Mukhidin, M., \& Hasan, B. (2016). Pengembangan Bahan Ajar Mata Pelajaran Dasar Dan Pengukuran Listrik Untuk Sekolah Menengah Kejuruan. Jurnal Pendidikan Teknologi .... 
239 Pemetaan Bibliometrik Terhadap Riset pada Sekolah Menengah Kejuruan Menggunakan VOSviewerHendra Sahputra Batubara, Muhammad Giatman, Wakhinuddin Simatupang, Ronal Watrianthos DOI: https://doi.org/10.31004/edukatif.v4i1.1818

Https://Journal.Uny.Ac.Id/Index.Php/Jptk/Article/View/9352

Moses, K. M. (2017). Hubungan Kerja Sama Antara Sekolah Menengah Kejuruan (Smk) Dengan Industri Di Bidangteknologi Informasi (Ti) Di Kota Malang. Repository.Um.Ac.Id. Http://Repository.Um.Ac.Id/Id/Eprint/61996

Oka, I. A. P. (2021). Pengaruh Kompetensi Guru Profesional Terhadap Prestasi Belajar Siswa Sekolah Menengah Kejuruan. Pijar: Jurnal Penelitian Bidang Pendidikan Dan .... Https://Journal.ActualInsight.Com/Index.Php/Pijar/Article/View/417

Putri, R. Y., \& Supriansyah, S. (2021). Pengaruh Literasi Digital Terhadap Kesiapan Kerja Generasi Z Di Sekolah Menengah Kejuruan. Edukatif: Jurnal Ilmu Pendidikan. Https://Www.Edukatif.Org/Index.Php/Edukatif/Article/View/1055

Rochayati, A. S., \& Hidayat, E. (2015). Faktor-Faktor Yang Mempengaruhi Perilaku Merokok Remaja Di Sekolah Menengah Kejuruan Kabupaten Kuningan. In Jurnal Keperawatan Soedirman. Jks.Fikes.Unsoed.Ac.Id. Http://Jks.Fikes.Unsoed.Ac.Id/Index.Php/Jks/Article/Viewfile/587/326

Saputra, W., Rusdinal, R., \& Gistituati, N. (2021). Kepemimpinan Demokratis Kepala Sekolah Di Sekolah Menengah Kejuruan. Edukatif: Jurnal Ilmu Pendidikan. Https://Www.Edukatif.Org/Index.Php/Edukatif/Article/View/996

Suliyanah, Adelia, B. D., Jauhariyah, M. N. R., Misbah, Mahtari, S., Saregar, A., \& Deta, U. A. (2021). A Bibliometric Analysis Of Minimum Competency Assessment Research With Vosviewer Related To The Impact In Physics Education On 2019-2020. Journal Of Physics: Conference Series, 2110(1), 012022. Https://Doi.Org/10.1088/1742-6596/2110/1/012022

Suryandari, D., Hidayah, R., Sukirman, Baroroh, N., \& Hajawiyah, A. (2021). Peningkatan Kompetensi Guru Akuntansi Sekolah Menengah Kejuruan Melalui Pengembangan Kewirausahaan. Jurnal Implementasi, l(1).

Susanto, H. (2012). Faktor-Faktor Yang Mempengaruhi Kinerja Guru Sekolah Menengah Kejuruan. Jurnal Pendidikan Vokasi. Https://Journal.Uny.Ac.Id/Index.Php/Jpv/Article/View/1028

Wibowo, N. (2016). Upaya Memperkecil Kesenjangan Kompetensi Lulusan Sekolah Menengah Kejuruan Dengan Tuntutan Dunia Industri. Jurnal Pendidikan Teknologi Dan Kejuruan. Https://Journal.Uny.Ac.Id/Index.Php/Jptk/Article/View/9354

Yu, Y., Li, Y., Zhang, Z., Gu, Z., Zhong, H., Zha, Q., Yang, L., Zhu, C., \& Chen, E. (2020). A Bibliometric Analysis Using Vosviewer Of Publications On Covid-19. Annals Of Translational Medicine, 8(13), 816816. Https://Doi.Org/10.21037/Atm-20-4235 